\title{
SUSTENTABILIDADE E QUALIDADE AMBIENTAL DE PROJETOS CORPORATIVOS EM FORTALEZA-CE
}

\author{
ARAUJO, Adriana Castelo Branco Ponte de \\ Instituto Federal do Ceará, acbranco2003@yahoo.com.br \\ GOMES, Cibele de Oliveira Parreiras \\ Centro Universitário Estácio, cibele@cibeleparreiras.arq.br \\ TOMAZ, Roberta Aguiar \\ Unifor, e-mail: robertaaguiartomaz@edu.unifor.br
}

\begin{abstract}
RESUMO
presente artigo analisou os principais indicadores de sustentabilidade e qualidade ambiental encontrados em projetos corporativos na cidade de Fortaleza-Ce. Foram avaliados alguns aspectos que definiram um roteiro para o processo projetual, servindo também de referência à obtenção de certificações internacionais. Os projetos estudados neste trabalho possuem características técnicas que atendem a preocupação com o meio-ambiente, além de priorizar o conforto de seus futuros usuários. A metodologia utilizada na pesquisa consistiu em uma revisão narrativa bibliográfica com estudos de casos. Concluiu-se que os projetos corporativos em questão demonstraram impacto ambiental e social positivo na comunidade local, contribuindo assim para o desenvolvimento de uma cidade sustentável.
\end{abstract}

Palavras chave: Arquitetura sustentável, Qualidade ambiental, Projeto Corporativo.

\begin{abstract}
The present article analyzed the main indicators of sustainability and environmental quality found in corporate projects in the city of Fortaleza-Ce. We evaluated some aspects that defined a roadmap for the design process, also serving as a reference for obtaining international certifications. The projects studied in this work have technical characteristics that attend to the concern with the environment, besides prioritizing the comfort of its future users. The methodology used in the research consisted of a bibliographical narrative review with case studies. It was concluded that the corporate projects in question demonstrated a positive environmental and social impact on the local community, thus contributing to the development of a sustainable city.
\end{abstract}

Keywords: Sustainable architecture, Environmental Quality, Corporate Design.

\section{INTRODUÇÃO}

O presente artigo visa analisar os principais indicadores de sustentabilidade e qualidade ambiental encontrados em projetos corporativos na cidade de Fortaleza-CE. Para alcançar o objetivo citado, realizou-se uma revisão bibliográfica e um estudo de caso de duas edificações que serviram para avaliar a realidade dos projetos sustentáveis em Fortaleza.

A palavra sustentabilidade vem do termo "sustentável" que deriva do latim "sustentare", significando sustentar, conservar e cuidar. Esse conceito teve origem na conferência das nações unidas sobre Meio Ambiente Humano que aconteceu em 1972 em Estocolmo. Assim, o termo "sustentabilidade" foi incorporado no meio político, empresarial e nos meios de comunicação da sociedade civil (LEITE, 2012).

ARAU JO, A. C. B. P.; GOMES, C. O. P.; TOMAZ, R. A. Sustentabilidade e qualidade ambiental de projetos corporativos em Fortaleza-CE. In: SIMPÓSIO BRASILEIRO DE QUALIDADE DO PROJETO NO AMBIENTE CONSTRUÍDO, 6., 2019, Uberlândia. Anais... Uberlândia: PPGAU/FAUED/UFU, 2019. p. 544-558. DOI https://doi.org/10.14393/sbqp19051. 
O marco do conceito de sustentabilidade no Brasil acontece na Cúpula da Terra do Rio de Janeiro (Eco-92), surgindo a Agenda 21 em 1992. No ano de 2003 foi elevada à condição de Plano Plurianual (2004-2007). A Agenda 21 é instrumento participativo que planeja o desenvolvimento sustentável, podendo este ser implantado do nível global ao municipal.

Atualmente, podemos destacar a atuação da GBC Brasil (Green Building Council Brasil), ONG que visa fomentar a indústria de construção sustentável no Brasil. A ONG tem a atribuição de promover a certificação internacional LEED (LEADERSHIP IN ENERGY AND ENVIRONMENTAL DESIGN) em 143 países. Atualmente $O$ Brasil é $\bigcirc 40$ país com maior número de registros no ranking mundial (GBC Brasil, 2019).

De acordo com a GBC Brasil a certificação LEED de um empreendimento pode promover diversos benefícios econômicos, ambientais e sociais.

Dentre os benefícios econômicos podemos destacar: diminuição de custos operacionais, redução do custo de manutenção da edificação, valorização do imóvel e de sua imagem, isenções fiscais, melhoria na produtividade dos ocupantes e menor obsolescência do edifício. Os prédios verdes possuem em média uma redução de energia de 30\% e economia de água em até $50 \%$, gerando assim taxas condominiais mais baixas.

Já quanto aos benefícios ambientais observa-se: uso racional dos recursos naturais durante a construção e operação; respeito a legislação de resíduos sólidos; redução de impactos para o meio ambiente e diminuição de CO2 na atmosfera com mitigação de efeitos das mudanças climáticas.

Os benefícios sociais gerados podem ser: preocupação com o entorno e vizinhança, melhoria da qualidade de vida, conforto, saúde e segurança dos operários e ocupantes; incentivo a fornecedores terem mais responsabilidade socioambiental e estímulo a políticas públicas de fomento a construção sustentável.

Na figura 1 constata-se um cenário geral das edificações certificadas no Brasil, destacando as localidades e as tipologias de empreendimentos. Observa-se que as edificações de escritórios e comerciais somam 49,5\% dos edifícios já certificados.

Registros por Tipologia
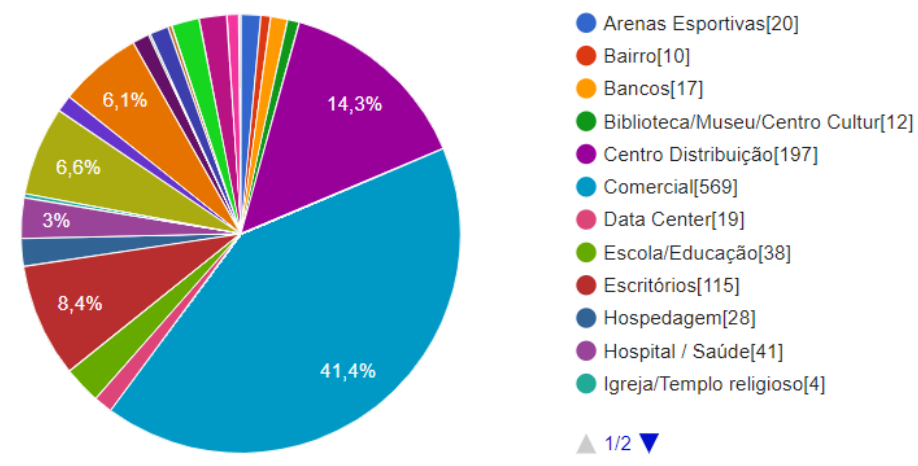

Industrial[90]

Laboratório[17]

Outros[84]

Público[17]

Teatro/Auditório[2]

Varejo[19]

Varejo: Concessionária[4]

Varejo: Restaurante[28]

Varejo: Shopping[28]

Varejo: Supermercado[12]

Outro

Figura 1 - Gráfico descritivo da tipologia certificados com o selo LEED no Brasil.

Fonte: GBC Brasil (2019) 
Observa-se na Figura 2 que o estado do Ceará possui uma discreta participação no contexto de edifícios certificados do Brasil, no entanto as construtoras locais estão, gradativamente, inovando nos lançamentos de edifícios ambientalmente corretos. Os projetos corporativos sustentáveis na cidade de Fortaleza se destacaram nos últimos seis anos, onde se evidenciaram o projeto de duas torres que buscaram atender os indicadores de sustentabilidade das certificações internacionais.

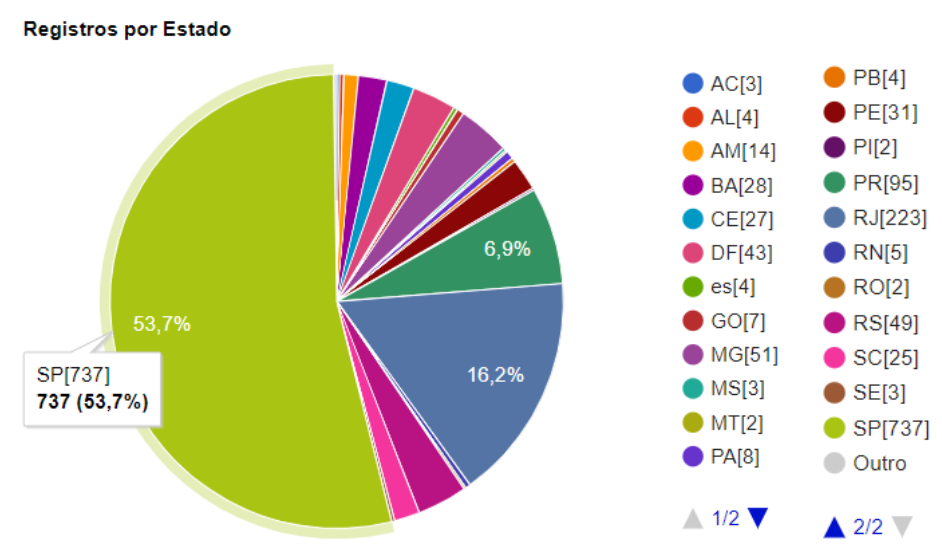

Figura 2 - Gráfico descritivo de empreendimentos certificados por estado com o selo LEED no Brasil.

Fonte: GBC Brasil (2019)

\section{FUNDAMENTAÇÃO}

Observa-se que na maioria dos países, entre eles, o Brasil, a busca pelo progresso econômico e social acaba por explorar de maneira indiscriminada os recursos naturais em vários setores, incluindo a construção civil, afetando, assim o meio ambiente (lpiranga et al., 2011).

O conceito de construção sustentável, segundo Adam (2001), é definido como sendo um conjunto de estratégias para utilização do solo, englobando tanto o projeto quanto a construção, visando a redução do impacto ambiental, bem como do consumo de energia, proporcionando, assim, maior proteção dos ecossistemas e consequentemente mais saúde para a população.

Dessa forma, a construção civil deve buscar a sustentabilidade, tendo em vista que cerca de $50 \%$ do resíduo sólido gerado pelas atividades humanas originase nessa indústria. Além disso, esse setor também é responsável pelo consumo de grande parte dos recursos naturais, gerando, assim, elevados impactos ambientais (MMA, 2019).

É importante, pois, a criação de ambientes construídos que sejam benéficos ao ser humano, causando menos danos físicos ou psicológicos, proporcionando a valorização das futuras gerações e do planeta em que habitam, através da concepção de espaços agradáveis e propiciadores de bem-estar (NUNES et al., 2019).

Na construção civil tem-se buscado cada vez mais estratégias de projeto para obter níveis satisfatórios de qualidade ambiental nas edificações. Algumas dessas estratégias são: controle de ganho de calor; dissipação da energia térmica do interior do edifício; remoção da umidade em excesso; promoção 
do movimento de ar e uso da iluminação natural e controle do ruído (CORBELLA; YANNAS, 2003).

A classificação quanto à sustentabilidade de um edifício inicia nas tomadas de decisão durante o projeto, onde o planejamento precisa antever as questões referentes às limitações urbanas, funcionais, técnicas, normativas e orçamentárias (JOURDA, 2013).

A sustentabilidade na construção civil deve incluir qualidade ambiental, funcionalidade, custo do ciclo de vida e impacto ambiental. Para isso, foram estipulados diversos selos para avaliar o padrão das construções sustentáveis, entre eles a certificação LEED, AQUA, Caixa AzUI, PROCEL edificações.

A certificação Leed é dividida em 8 dimensões e analisa diversos tipos de projetos. Todas as dimensões possuem pré-requisitos (práticas obrigatórias) e créditos (recomendações) e à medida que são atendidas, garantem pontos à edificação. O nível da certificação é definido conforme os pontos adquiridos, podendo ser classificado em: Certificado, Silver, Gold e Platinum. As dimensões consideradas neste processo de certificação são: Localização e Transporte; Espaços Sustentáveis, Eficiência do Uso da Água; Energia e Atmosfera; Materiais e Recursos; Qualidade Ambiental Interna; Inovação e Processos; e Créditos de Prioridade Regional.

\section{METODOLOGIA}

A metodologia utilizada na pesquisa consistiu primeiramente em realizar uma revisão bibliográfica sobre os conceitos importantes na certificação de construções sustentáveis para, posteriormente, aplicar um check-list de análise em dois edifícios corporativos de Fortaleza selecionados para estudo de caso. Este check-list foi elaborado a partir de critérios definidos para cada dimensão da Certificação LEED que será considerada para os edifícios apresentados.

\section{RESULTADOS}

\subsection{Análise do Edifício Corporativo "A"}

O Edifício "A" foi inaugurado em 2014, sendo o primeiro edifício corporativo da cidade a receber a certificação Leed, alcançando a pontuação prata. Sua área total construída é de $32436,97 \mathrm{~m}^{2}$ e o terreno possui $3760,93 \mathrm{~m}^{2}$, tendo $1121,54 \mathrm{~m}^{2}$ de área verde. Ao todo são 24 pavimentos, sendo 19 pavimentos tipo e 5 pisos de garagem (ver figura 3).

Foram analisadas as seguintes dimensões LEED nesta edificação: Localização e Transporte; Espaços Sustentáveis; Uso Racional da Água; Energia e Atmosfera; Materiais e Recursos; Qualidade Ambiental Interna e Inovação e Processos. 


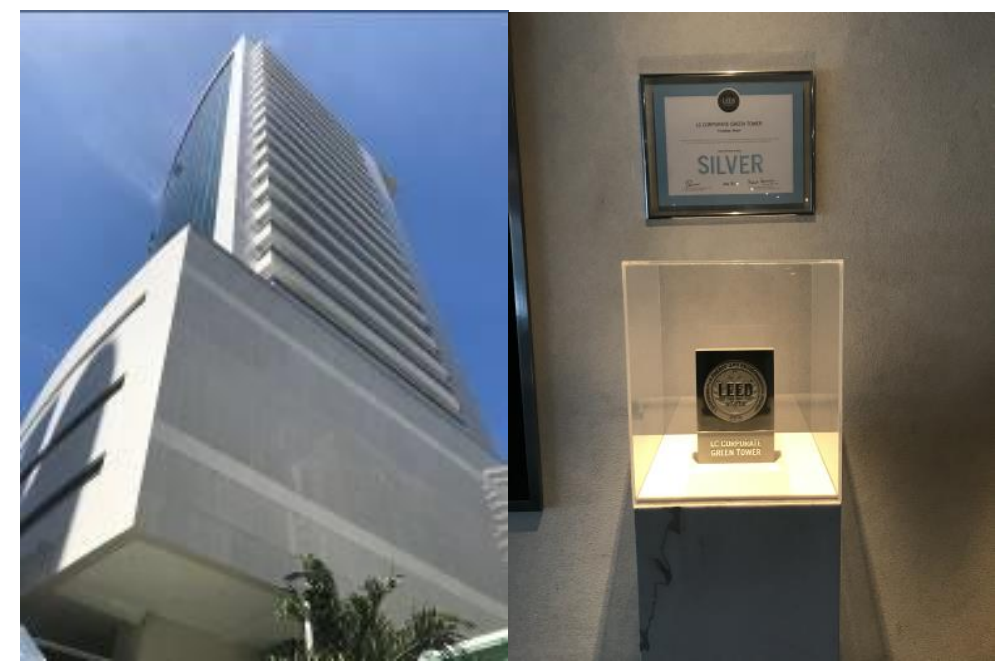

Figura 3 - Fachada do edifício "A" e Placa de certificação

Fonte: Registro dos autores (2019)

Em relação à dimensão Localização e Transporte, observou-se a proximidade de transporte público e estação de bicicletas compartilhadas (figura 4), assim como a proximidade com outros estabelecimentos comerciais e restaurantes, o que evita deslocamentos dos usuários durante o dia. Também existem as facilidades de bicicletários interno e externo (figura 5).

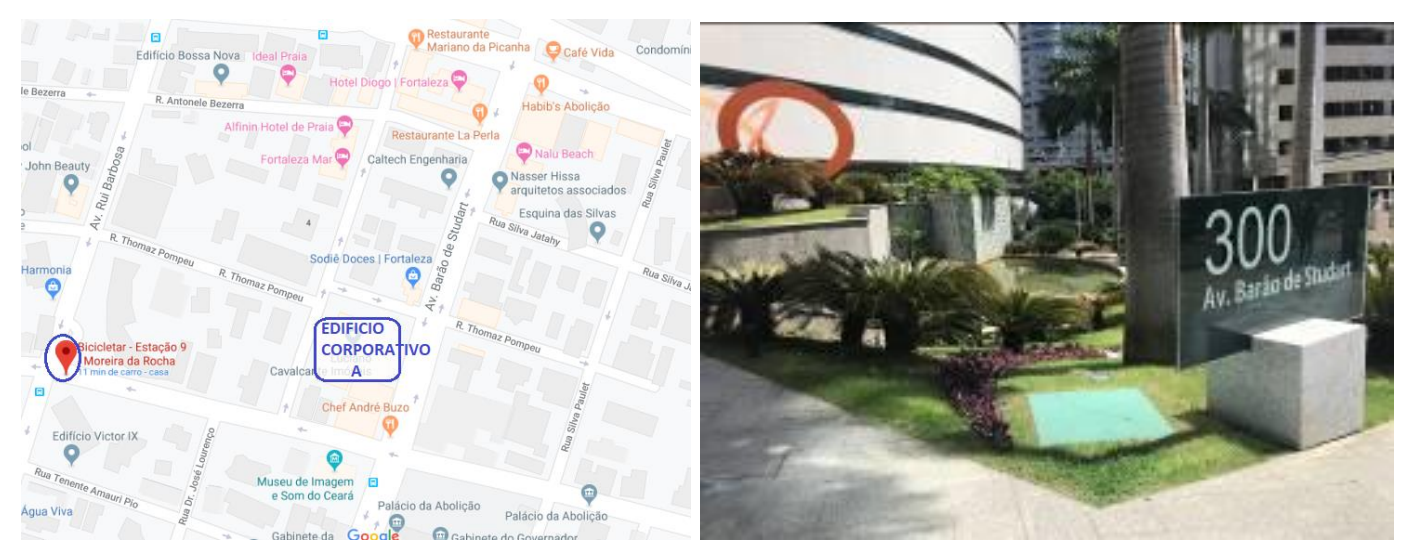

Figura 4 - Localização do edificio

Fonte: Google Maps adaptado pelas autoras e Registro dos autores (2019)

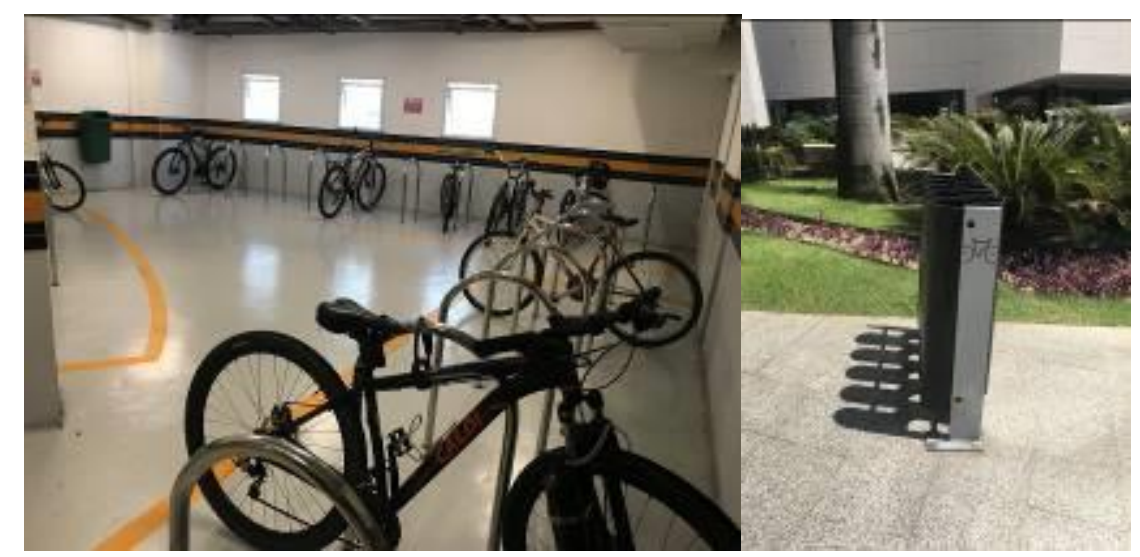

Figura 5 - Bicicletário interno e externo.

Fonte: Registro dos autores (2019) 
Na dimensão Espaços Sustentáveis houve, durante a construção, a preocupação em prevenir a polvição através do tipo de concreto, segregação de resíduos e uso controlado da água, tratando a parte contaminada (figuras 6). Existe também na edificação uma estação de tratamento para reaproveitamento das águas pluviais que são utilizadas para irrigação e alimentação das descargas dos sanitários até o quarto pavimento. Alguns espaços, como os subsolos, possuem exaustão permanente com equipamentos que medem a taxa de $\mathrm{CO} 2$ e, dependendo do nível, o exaustor é acionado para a renovação do ar (figura 7). O uso de vidros insulados em toda a fachada reduziu a ilha de calor devido sua película que absorve apenas a luminosidade, diminuindo também o consumo dos condicionadores de ar. Observou-se ainda que o uso da iluminação indireta nas fachadas e nos jardins facilitou a redução da polvição luminosa no local.
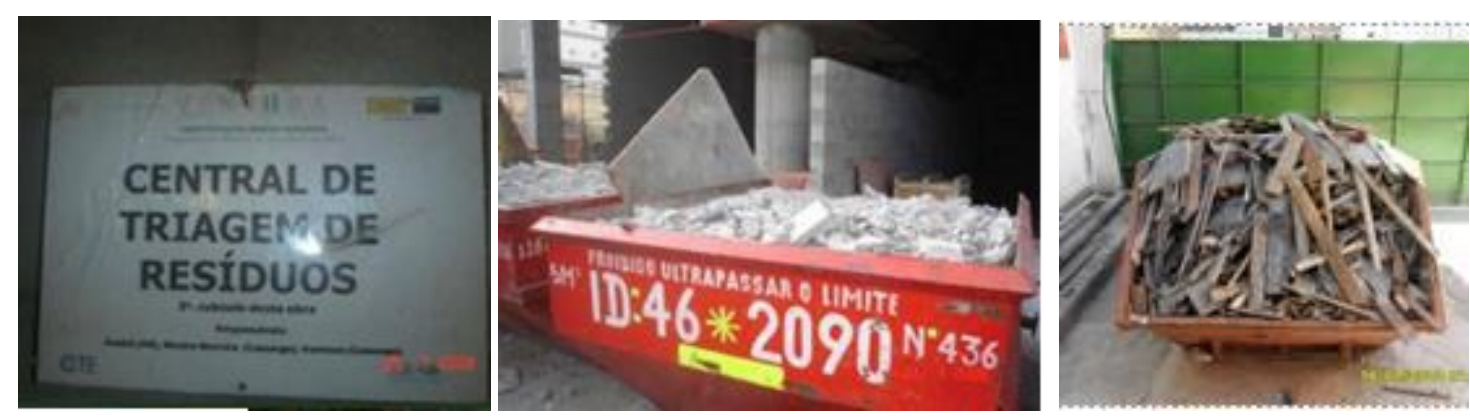

Figura 6 - Triagem de resíduos durante a obra

Fonte: Arquivo da construtora (2012)
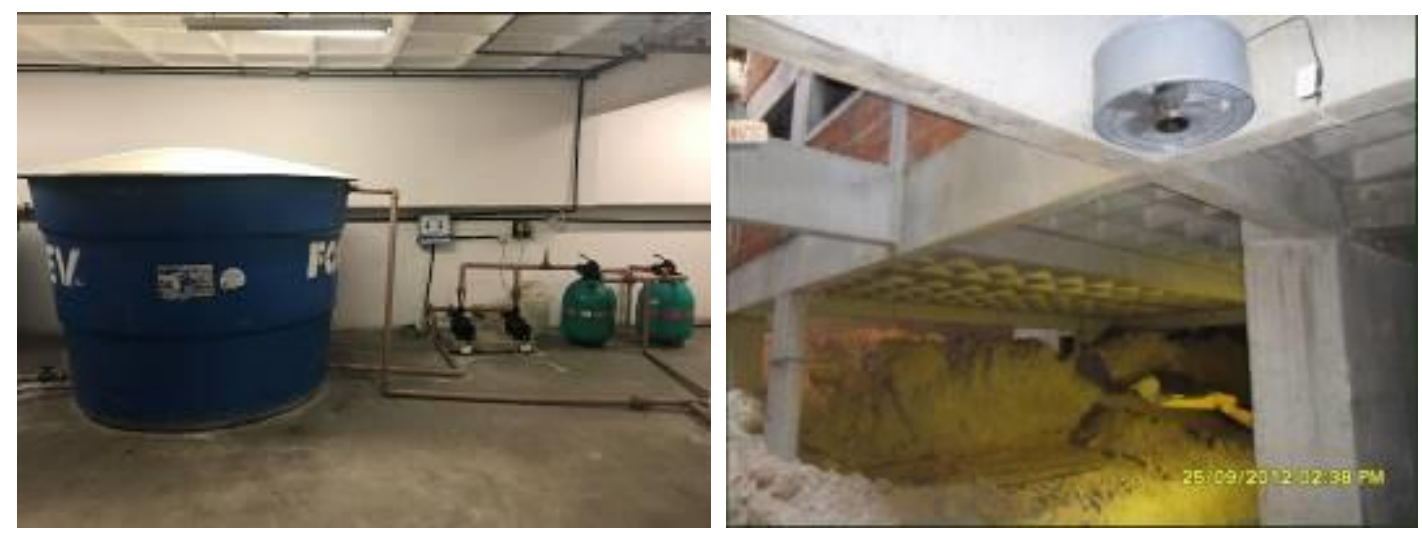

Figura 7 - Estação das águas pluviais e Exaustor no subsolo

Fonte: Arquivo da construtora (2012

Na dimensão Uso Racional da Água, existe uma redução no consumo de água nas torneiras graças ao uso de aeradores nas descargas com duplo acionamento, além do reuso da água para irrigação e descargas (conforme mencionado anteriormente). Nos jardins, além das águas pluviais são também reutilizadas as águas dos drenos dos ar-condicionados (aproximadamente 4000 litros por dia), sendo a estação de tratamento a responsável por esses reusos, reduzindo, dessa forma, a quantidade de água da chuva lançada na rede pública(figura 8). 


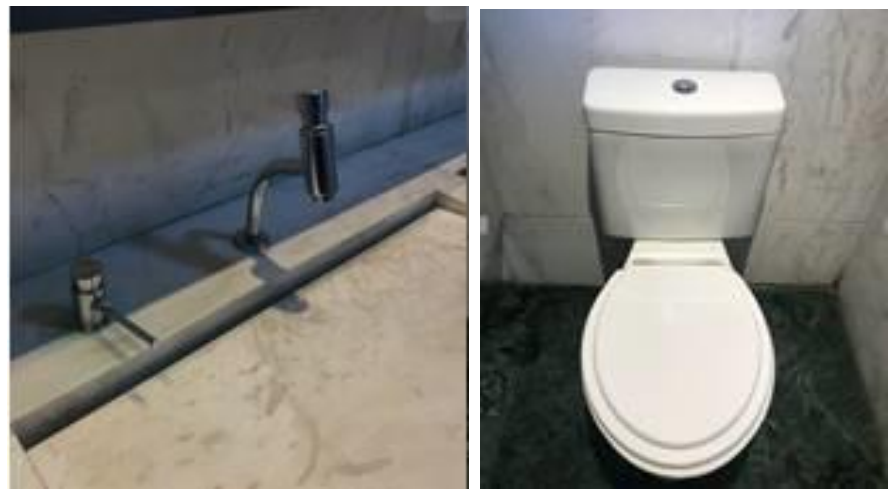

Figura 8 - Torneiras e descargas

Fonte: Registro dos autores (2019)

Outra dimensão analisada foi Energia e Atmosfera, onde foram observadas soluções que reduzem o consumo energético como os vidros insulados, o sistema de ar condicionado VRF (economia de 40\%), lâmpadas de led, elevadores tipo Miconic e automação (figura 9). Não houve, porém, nessa edificação a utilização de fontes renováveis de energia como as placas solares, devido à falta de espaço físico para a acomodação das mesmas. Em relação à redução de emissão de gases prejudiciais à camada de ozônio, existiu toda uma preocupação com a utilização de produtos na pintura com VOC abaixo do limite determinado pela legislação, além de outros materiais sustentáveis (figura 10).
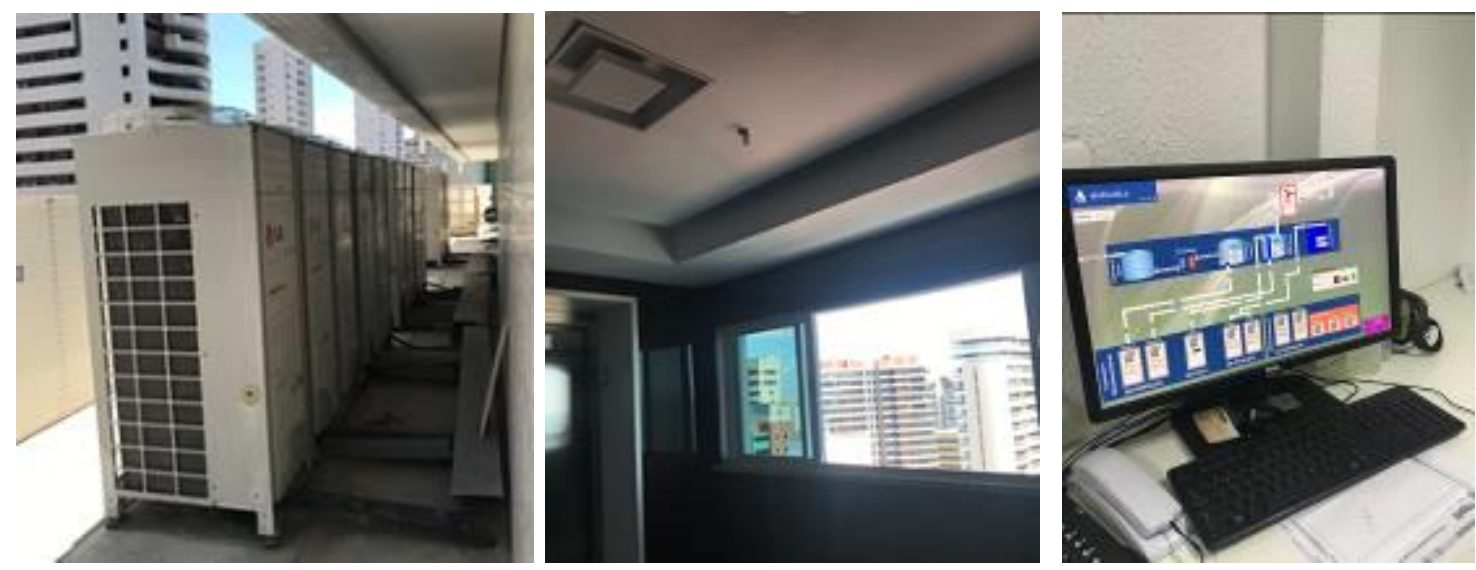

Figura 9 - Sistema de ar condicionado, iluminação led, elevadores e automação Fonte: Registro dos autores (2019)

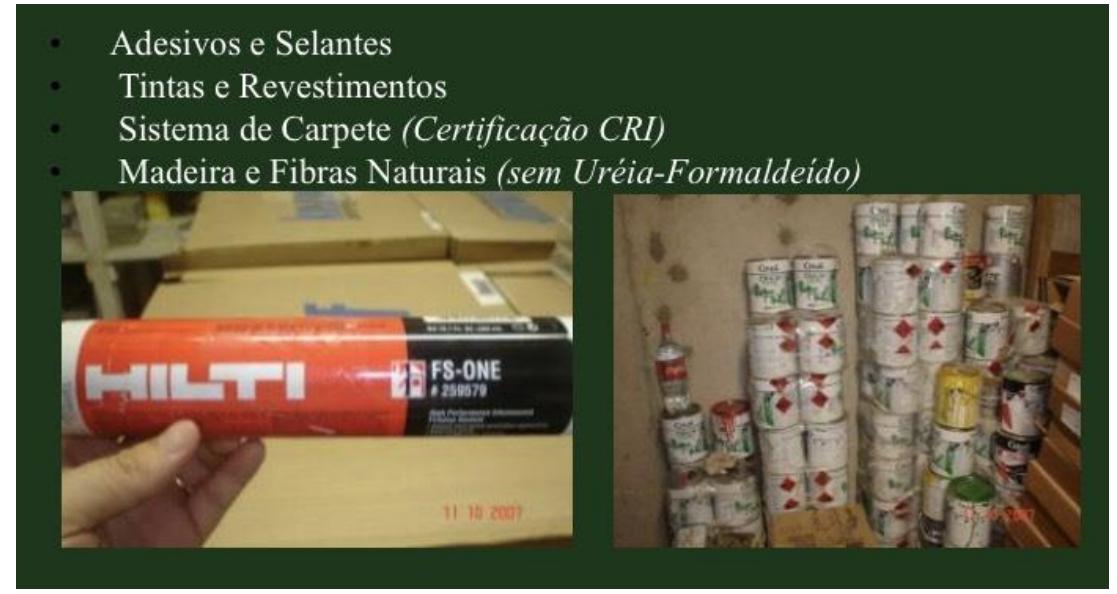

Figura 10 - Materiais com preocupações sustentáveis Fonte: Arquivo da construtora (2012) 
Na dimensão Materiais e Recursos, foi realizado depósito e coleta de materiais recicláveis que são encaminhados para uma usina de reciclagem, sendo separados os segregados dos reaproveitáveis. Durante a obra existiu também um programa de gestão de resíduos onde até a quantidade era gerida para não ultrapassar o máximo permitido por funcionário. Além disso, todos os materiais utilizados na obra tinham que possuir certificação ambiental - a madeira, o aço, o granito, o porcelanato, sendo a maioria fabricada a uma distância de no máximo $800 \mathrm{~km}$ fortalecendo, assim, as indústrias regionais (figura 11). Observou-se, também, a utilização de espécies nativas no paisagismo, valorizando a cultura local (figura 12). Alguns materiais de acabamento quando necessitam ser substituídos são encaminhados para indústria de reciclagem, sendo reutilizados e não descartados após o primeiro uso.

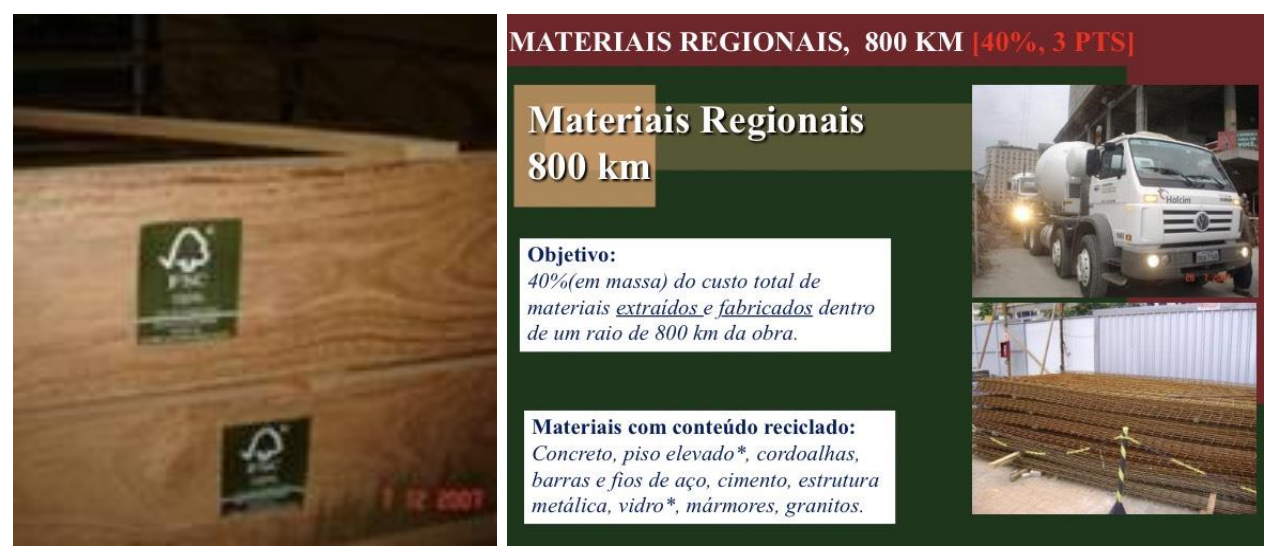

Figura 11 - Madeira certificada e materiais regionais. Fonte: Arquivo da construtora (2012)

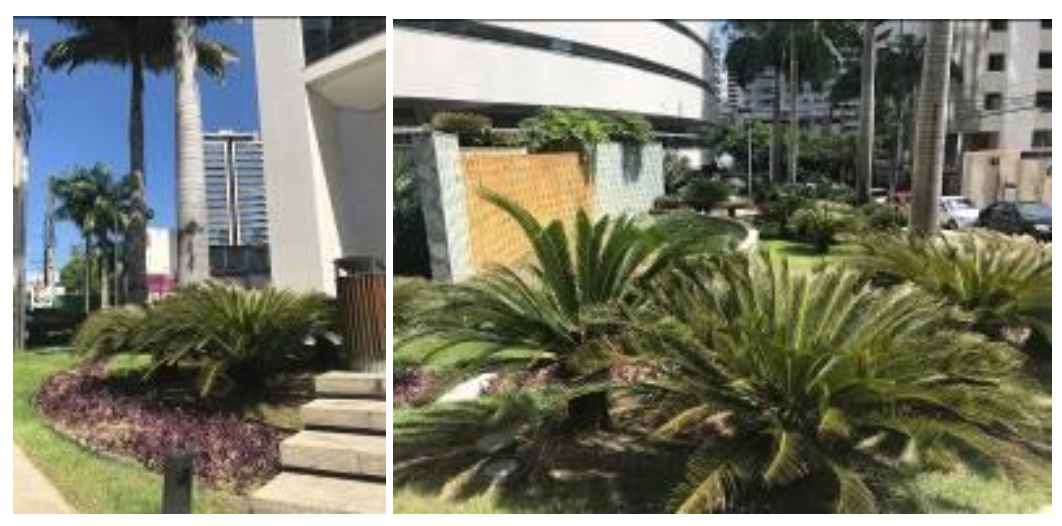

Figura 12 - Paisagismo com espécies nativas Fonte: Registro das autoras (2019)

Analisando a dimensão Qualidade Ambiental Interna, verificou-se que, em relação à qualidade do ar interno, existe um sistema de desumidificação que insufla $O$ ar filtrado nas salas além do exaustor que retira o ar poluído, renovando o ar e deixando-o mais saudável (figura 13). Em relação à redução de emissão de gases prejudiciais á camada de ozônio, o gás utilizado no sistema VRF de ar condicionado além de não prejudicar a camada d e ozônio, reduz o consumo de energia. Há detectores em todos os pavimentos para o controle da fumaça de cigarro e, durante toda a construção, não era 
permitido fumar dentro da obra. Com relação à ventilação natural, observa-se maiores aberturas nos subsolos e circulações facilitando a maior circulação de ar (figura 13). O conforto térmico da edificação é adquirido devido ao vidro insulado na fachada e ao porcelanato não aderido (rejuntado com silicone nas bordas). Na coberta foi utilizada uma membrana impermeável, de cor branca, que reflete os raios solares e não esquenta a edificação. A iluminação natural é obtida através do uso do vidro que permite maior entrada de luz tanto nas salas quanto nas circulações. O edifício possui vista para o mar, sendo de extrema qualidade visual (figura 14). O desempenho acústico também é alcançado com o vidro insulado, devido a uma camada de ar no seu interior. A presença de espaços flexíveis foi observada nas salas de eventos e no auditório (figura 14).
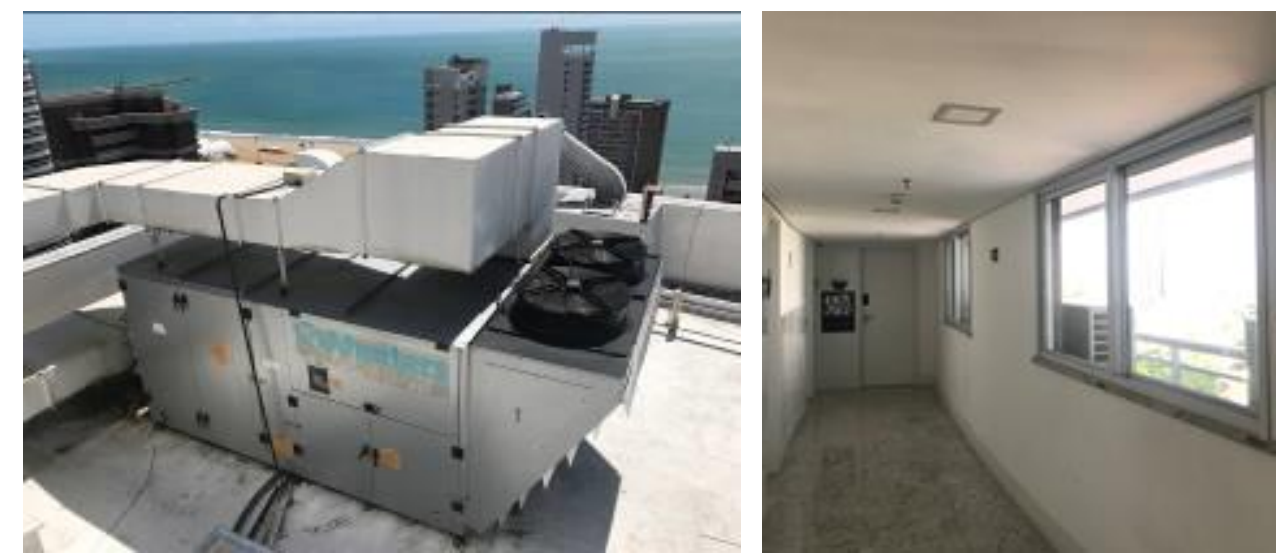

Figura 13 - Exaustão/desumidificação do ar e lluminação natural Fonte: Registro dos autores (2019)

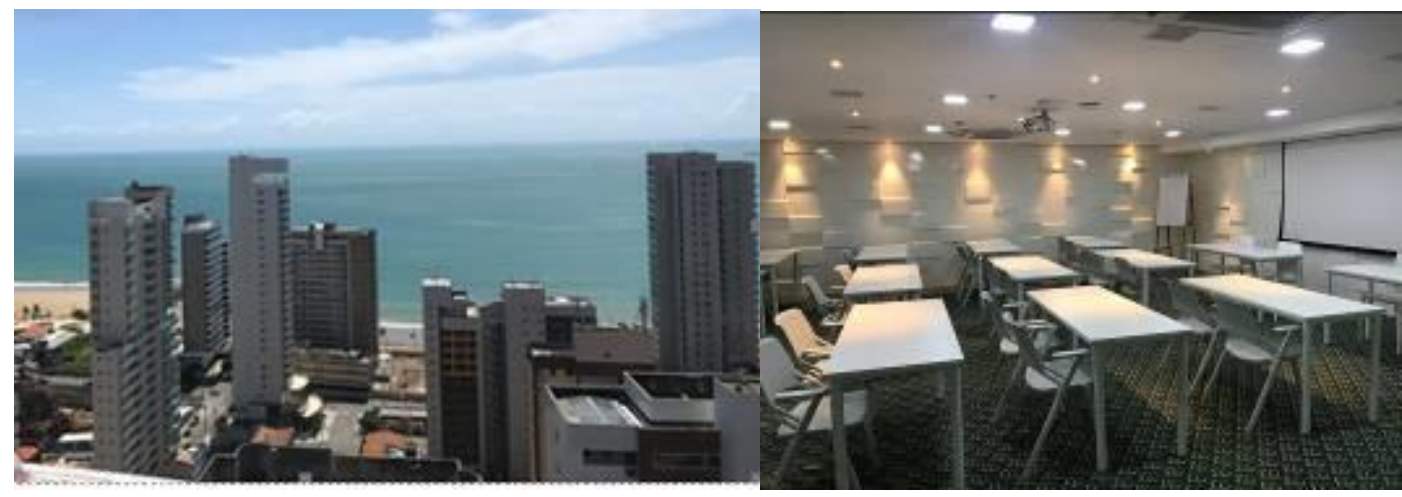

Figura 14 - Qualidade visual e Flexibilidade dos espaços

Fonte: Registro dos autores (2019)

Em relação à Inovação e Processos, ocorreu inovação no processo de projeto através da automação planejada para um melhor controle da edificação.

\subsection{Análise do Edifício Corporativo "B"}

O Edifício "B" foi inaugurado em março de 2019 e possui aproximadamente 72 mil $\mathrm{m} 2$ de área construída implantado em um terreno de $10.000 \mathrm{~m} 2$, onde grande parte do térreo foi destinado a ser uma praça de convívio público-privado. Esta praça garante $360^{\circ}$ de 
vista e possui largas calçadas em piso tátil e rampas de acessibilidade. O projeto do edifício foi idealizado, desde a sua concepção, para obter a certificação LEED, tendo recebido também a chancela internacional $A+$ devido à inteligência e alto padrão de tecnologia, segurança e conforto.
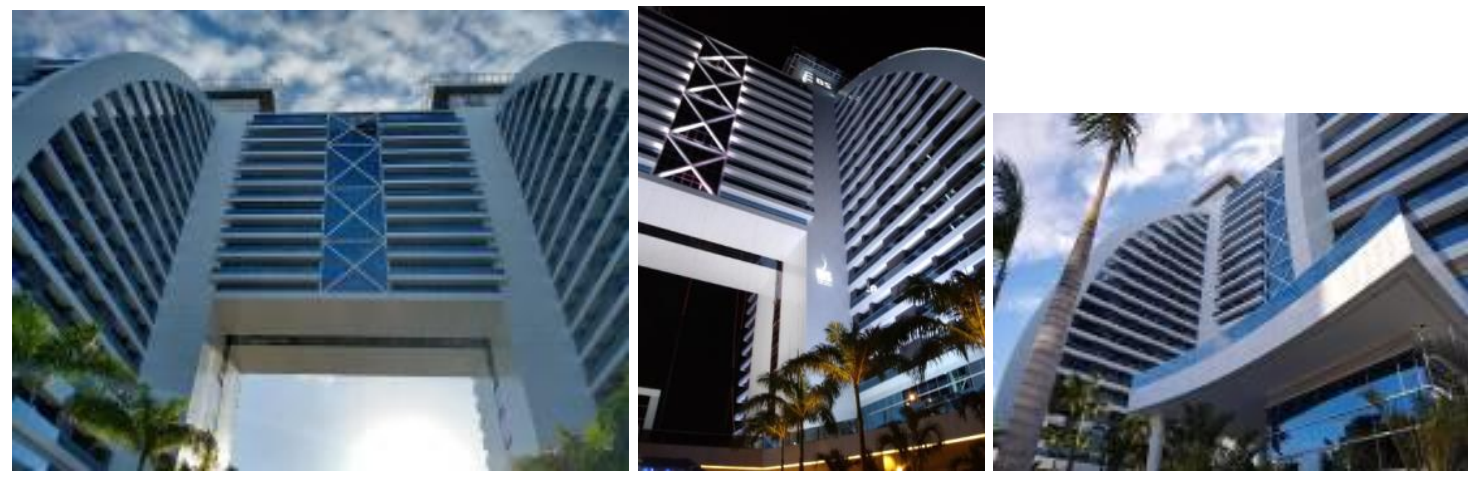

Figura 15 - Visão Diurna e noturna da edificação Fonte: Registro dos autores (2019)

O edifício é composto de duas torres com acessos independentes, sendo interligadas por duas grandes lajes corporativas que criam um vão central livre com pé-direito de 35 metros. O projeto apresenta soluções diversas de layouts disponibilizando espaços que variam de $22,70 \mathrm{~m} 2$ a $326,47 \mathrm{~m} 2$ (figura 15).

Aqui foram consideradas as seguintes dimensões LEED: Localização e Transporte; Espaços Sustentáveis; Uso Racional da Água; Energia e Atmosfera; Materiais e Recursos e Qualidade Ambiental Interna.
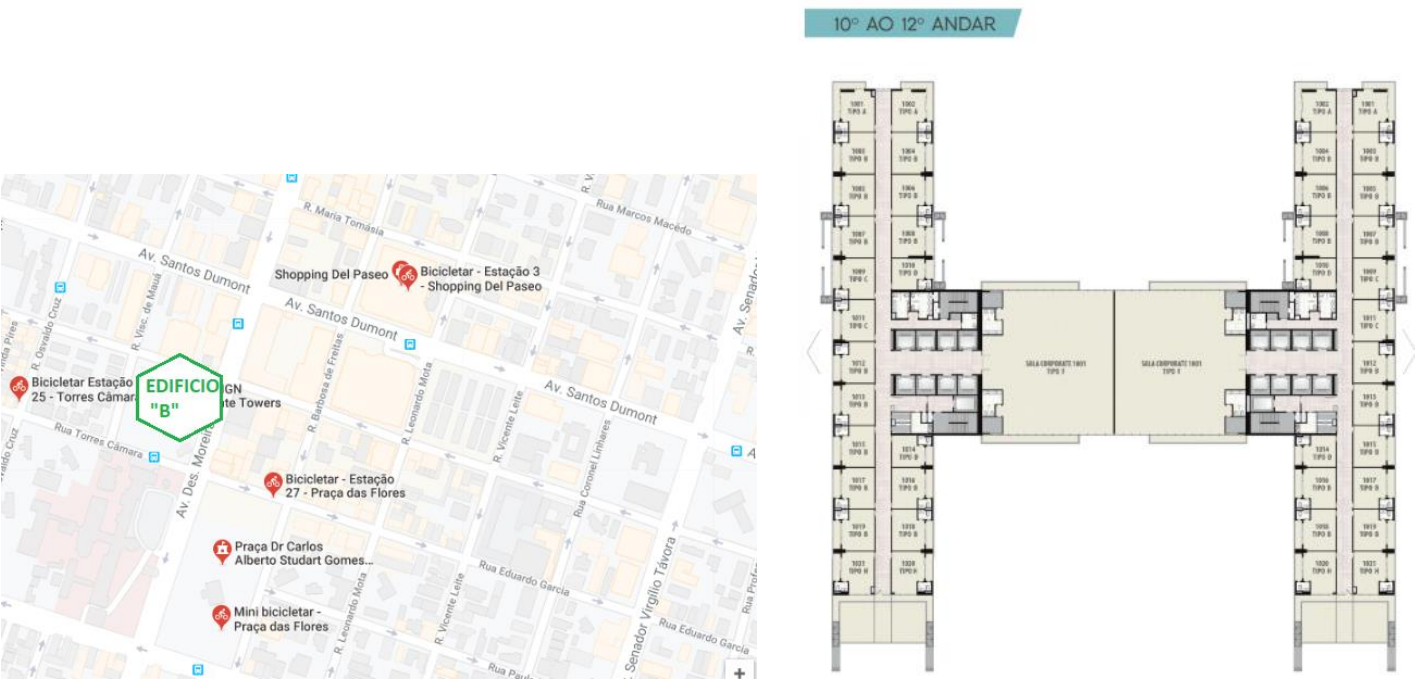

Figura 16 - Localização do Edificio e Planta baixa pavto tipo da torre Fontes: Google Maps adaptado pela autora (2019) e_http://bsdesign.com.br/plantas/(2019)

Com relação à Localização e Transporte, foram identificadas e analisadas a proximidade aos transportes públicos, assim como a presença de bicicletários. O edifício localiza-se próximo de vias de grande fluxo (Av. Desembargador Moreira e Av. Santos Dumont), com diversas paradas de ônibus na região, sendo também próximo a bancos, shoppings, restaurantes, o que já evita muitos deslocamentos dos ocupantes. O edifício está próximo de três estações de bicicletas compartilhadas sendo a mais próxima 
cerca de 50 metros (figura 16). Além disso, o edifício possui um bicicletário interno próprio com vestiário para seus usuários.

O primeiro subsolo tem um pé-direito ampliado com, aproximadamente, cinco metros, permitindo o processo de carga e descarga de veículo do tipo VUC, reduzindo o impacto no entorno. Há, ainda, dois acessos de desembarque para as pessoas que acessam o edifício. Conta com um "Green Parking" com vagas exclusivas para carros elétricos e vagas para veículos de baixa emissão (ver figura 17).
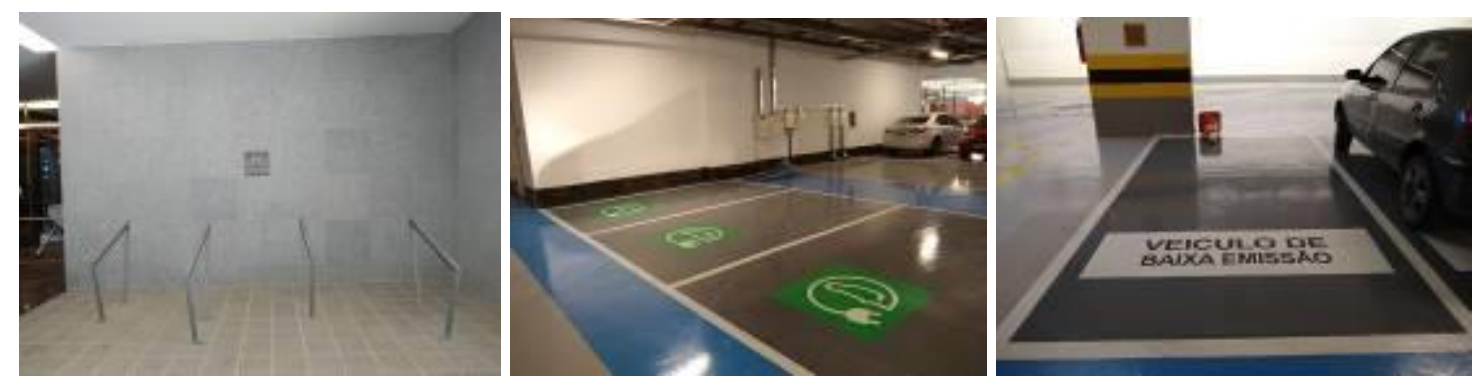

Figura 17 - Estacionamento subsolo com Bicicletário, vagas de carros elétricos e baixa emissão

Fonte: Registros das autoras (2019)

A dimensão de Espaços Sustentáveis foi atendida no item "Prevenção da polvição na atividade da construção", pois a obra produziu pouca poeira no seu entorno quando foram feitas as escavações, as vias de circulação dentro do canteiro foram umidificadas e os taludes protegidos. Houveram tentativas de mitigar os impactos no entorno do empreendimento com o trânsito de caminhões durante a obra entre 20:00h e 5:00h. Com relação a redução de ruídos, o transporte de terra era realizado por veículos credenciados (vistoriados pelo Inmetro) e sem sinais sonoros.

Esta dimensão também atendeu ao item "Redução de ilhas de calor", pois na área externa da praça aplicou um piso com baixa absorção de calor, com índice de refletância controlada, além da presença de áreas ajardinadas e espelhos d`água.

No que diz respeito à dimensão Eficiência do Uso da Água, foram observados algumas soluções de reuso da água e instalação de dispositivos hidráulicos eficientes (torneiras, mictórios e vasos sanitários) que influenciam diretamente na redução do consumo.

Para o item de "Tecnologias inovadoras para águas servidas", no período de escavações da obra, a água retirada do lençol freático era reaproveitada. Também durante a execução, a água utilizada para lavar as rodas dos caminhões evitava que estes levassem resíduos da obra para as vias públicas, onde parte desta água era reutilizada. Nos banheiros dos operários toda água usada nas pias era destinada para a descarga dos mictórios.

Para o item "Uso eficiente de água no paisagismo", as águas produzidas pelos ar-condicionados do edifício são reaproveitadas na irrigação das áreas verdes externas através de gotejamento. 
Já o item "Redução do consumo de água", foi atendido com a instalação de torneiras com válvula redutora de vazão e os vasos sanitários usam a descarga Dual Flush de 3/6 litros que podem evitar desperdícios.

A dimensão de Energia e Atmosfera analisa a eficiência energética, a utilização de combustíveis fósseis, de fontes renováveis de energia, assim como o incentivo à redução de emissão de gases prejudiciais à camada de ozônio. A eficiência energética foi analisada de forma criteriosa através da consultoria de um Comissionamento Energético que orientou todas as decisões de projeto.

Os vidros das fachadas são reflexivos e de alta performance, possuem tratamento UV que permitem a maior incidência de luz e eliminam $74 \%$ do calor, resultando na racionalização do uso de luz e ar-condicionados. Foram especificadas lâmpadas de LED com baixo consumo em todas as áreas comuns, inclusive no subsolo, além de luminárias de alta eficiência.

Um sistema de automação faz o controle de iluminação de fachadas, iluminação das áreas comuns, pressurização e acionamento das bombas de água. Os elevadores trazem o moderno sistema de frenagem regenerativa KERS, o mesmo usado nos carros da fórmula 1, gerando redução de até $40 \%$ de energia, e funcionam por sistema de antecipação que aciona 0 equipamento mais próximo do local de chamada. Na figura 18 observamos a placa que informa a expectativa de redução energética do edifício. Quanto ao item "Redução de emissão de gases prejudiciais a camada de ozônio", foram especificados condensadores para os equipamentos de arcondicionado que não utilizam CFC.
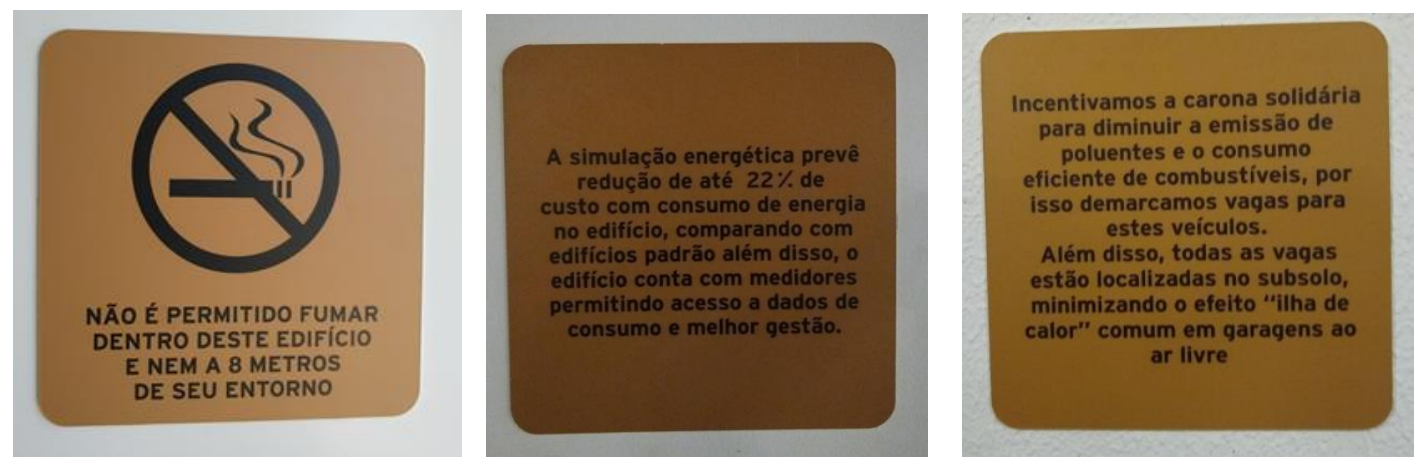

Figura 18 - Placas de comunicação visual no subsolo com indicadores sustentáveis Fonte: Registros das autoras (2019)

Sobre a dimensão Materiais e Recursos, foram analisados a presença de coleta seletiva e programa de gestão de resíduos; a especificação e utilização de materiais que possuem algum tipo de certificação ambiental; e a utilização de produtos e materiais que incentivam o reuso adaptável e otimizam o desempenho ambiental. $O$ edifício atendeu adequadamente ao programa de gestão de resíduos durante a obra, deixando posteriormente espaços para coleta seletiva de resíduos nos pavimentos tipo do edifício. Possui ainda uma central das diversas categorias de lixo(Ver figura 19). 

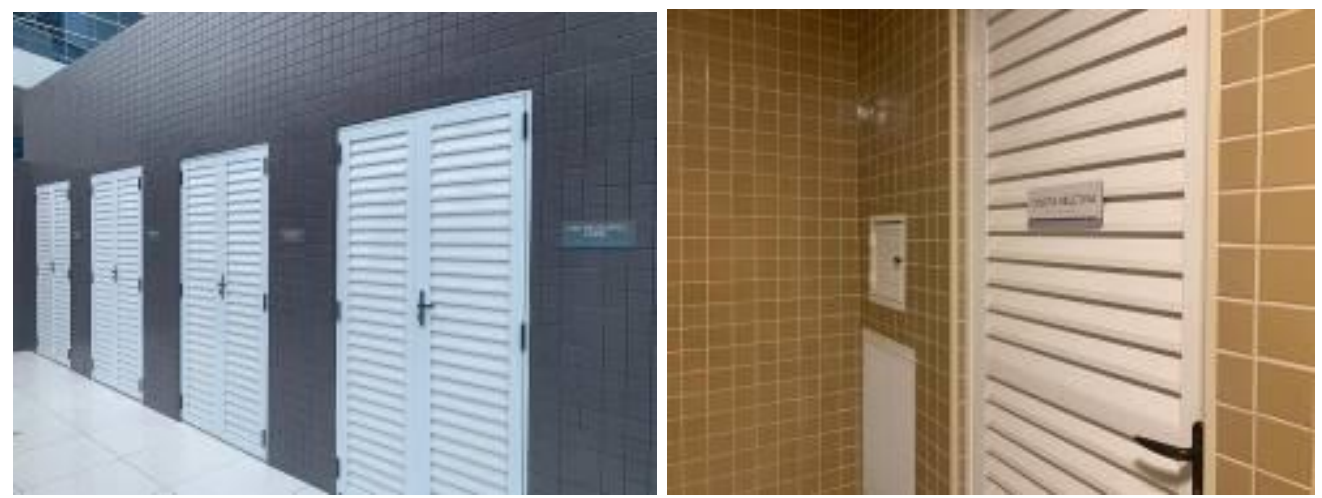

Figura 19 - Local da Coleta seletiva no acesso externo

Fonte: Enviado pela construtora (2019)

Com relação a utilização de produtos que apresentam certificação ou possuem características sustentáveis destacamos o quadro abaixo:

\section{Quadro 01 - Produtos sustentáveis especificados}

\begin{tabular}{|l|l|l|}
\hline Produto & Local Aplicado & Certificação ou Característica sustentável \\
\hline Carpete & $\begin{array}{l}\text { Circulações e salas } \\
\text { de reunião }\end{array}$ & $\begin{array}{l}\text { Selo Green Label Plus -Baixa emissão de orgânicos } \\
\text { voláteis (VOC's) }\end{array}$ \\
\hline Cerâmicas & Paredes e pisos & Produção sem emissão de VOCs \\
\hline Aço & Estrutura & Produzido com 20\% de material reciclado \\
\hline Aluminio & Janelas da fachada & Produzido com 100\% de material reciclado \\
\hline
\end{tabular}

Também foram utilizados "materiais regionais" que simbolizam os materiais que são adquiridos até uma distância de $800 \mathrm{~km}$ da obra. Nesse cenário foram especificados dois tipos de granitos que vieram da região do Vale do Acaraú e de Santa Quitéria (municípios do Ceará). Também foi adquirido cimento da fábrica Apodi produzido no município de Pecém-CE. É importante ressaltar que o paisagismo priorizou a utilização de espécies regionais nos jardins da praça (ver figura 20).

No que diz respeito à dimensão Qualidade Ambiental Interna, foram analisadas as condições de ventilação (natural e mecânica), espaço para fumantes, conforto térmico, vistas de qualidade e desempenho acústico.

A qualidade do ar interno é controlada através de sistema de renovação de ar nas áreas comuns, banheiros e garagens. A ventilação natural acontece em todas as circulações dos pavimentos tipos por meio de janelas nas entradas e saídas dos espaços(figura 20). 

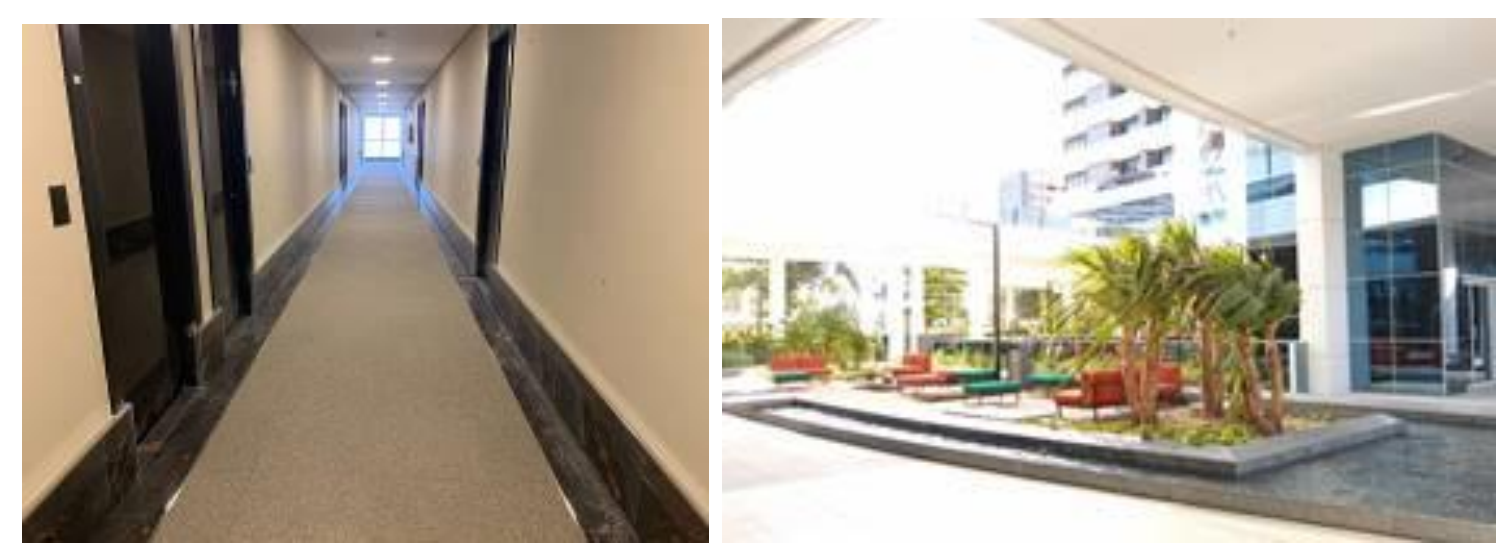

Figura 20- Circulação interna e Praça com paisagismo

Fonte: Enviado pela construtora (2019)

O uso do cigarro é recomendado que só aconteça a 8 metros de distância dos ambientes internos, conforme indica placa de comunicação visual na figura 18. Também existe um sistema de extração de fumaça em todos os pavimentos.

O conforto térmico é atendido no envoltório da fachada pela aplicação de vidros refletivos, além da coberta de alumínio pintada de branco para ter alta refletância e pouca absorção de calor. As Vistas de qualidades foi um item bem solucionado, pois os diversos lay-outs sugeridos nas salas permitem que seus ocupantes tenham o privilégio de olhar para a paisagem exterior.

O desempenho acústico é solucionado a partir da instalação de paredes em Dry Wall com chapas duplas e uso de carpetes nos corredores.

Os espaços são flexíveis pois os pavimentos tipo trazem salas com pédireito de 3,15 metros, com shafts visitáveis, utilizando também piso elevado nos pilotis, nas áreas de circulação internas, além de previsão para piso elevado nas salas, proporcionando baixo custo de manutenção.

\section{CONSIDERAÇÕES FINAIS}

Ambos os projetos das edificações corporativas "A" e "B" analisadas nessa pesquisa, atenderem às dimensões estabelecidas pela certificação LEED, tais como: Localização e Transporte; Espaços Sustentáveis; Uso Racional da Água; Energia e Atmosfera; Materiais e Recursos e Qualidade Ambiental Interna.

Após a realização de entrevistas com os responsáveis pela execução das obras, verificou-se que ambas contribuíram para o conforto dos usuários e a qualidade ambiental de seus espaços. Para a cidade de Fortaleza, esses edifícios representam um marco, pois impactam positivamente na cidade $e$ contribuem para o equilíbrio do ecossistema e bem-estar da comunidade.

\section{AGRADECIMENTOS}

Aos engenheiros Rafael Gomes, Raquel Botelho e Maria Thereza Leite da Construtora BSPAR e ao engenheiro Ricardo Fontenele da Construtora Caltech pela esmerada atenção nas entrevistas e envio de fotos das obras analisadas. 


\section{REFERÊNCIAS}

ADAM, Roberto Sabatella. Princípios do Ecoedifício: Interação entre Ecologia, Consciência e Edifício. 1.ed. São Paulo: Aquariana, 2001.

CORBELLA, Oscar; YANNAS, Simos. Em Busca de uma Arquitetura Sustentável. Rio de Janeiro: Revan, 2003.

GBC Brasil. Disponível em: < http://www.gbcbrasil.org.br/sobre-gbc.php> Acesso em; 16 mar. 2019

IPIRANGA, Ana Sila Rocha; GODOY, Arilda Schmidt; BRUNSTEIN, Janette. Introdução. RAM. REVISTA DE ADMINISTRAÇÃO MACKENZIE. Disponível em < http://www.scielo.br/pdf/ram/v12n3/a02v12n3.pdf>. Acesso em: 02 mar. 2019.

JOURDA, Françoise-Hélène. Pequeno Manual do Projeto Sustentável. São Paulo: Gustavo Gili, 2013.

LEITE, Carlos. Cidades Sustentáveis Cidades Inteligentes. Porto Alegre: Bookman, 2012.

MINISTÉRIO DO MEIO AMBIENTE. Construções sustentáveis. Ministério do Meio Ambiente(MMA). Disponível em: <http://www.mma.gov.br/cidadessustentaveis/areas-verdes-urbanas/item/10317-eixos-temáticos-construçõessustentáveis>. Acesso em: 02 mar. 2019

NUNES, Ilda Helena Oliveira; CARREIRA, Luzimeire Ribeiro de Moura; RODRIGUES, Waldecy. A Arquitetura Sustentável nas edificações urbanas: uma análise econômico-ambiental. Arquitetura Revista, v.14, n.1 (2018). Disponível em:<http://revistas.unisinos.br/index.php/arquitetura/article/view/4800/2062>. Acesso em: 02 março 2019 